\title{
THE ROLE OF TRAIT EMOTIONAL INTELLIGENCE IN THE PROCESS OF CAREER DECISION-MAKING ${ }^{1}$
}

\author{
Eva Sollarova, \& Lada Kaliska \\ Department of Psychology, Faculty of Education, Matej Bel University in Banska Bystrica (Slovakia)
}

\begin{abstract}
The process of career decision-making is an important experience in the adolescent's period often manifested by decision-making difficulties. The study analyzes the influence of trait emotional intelligence (TEI) in the process of career decision-making, especially on career decision-making difficulties, career decidedness and career decision self-efficacy (CDSE) assessed in a sample of high school students during their $2^{\text {nd }}$ career choice orientation testing. TEI as defined by Petrides (2009) and CDSE as defined by Betz et al. (1996), representing more stable personality-related variables, were studied in the context of career decision-making covering both more stable variables (emotional and personality-related aspects of career decision-making difficulties as specified by Saka, Gati \& Kelly, 2008) and more developmental variables (career decidedness as defined by Lounsbury \& Gibson, 2011). The study aims at the trait EI prediction level (as a personality trait) assessed by Trait Emotional Intelligence Questionnaire - Short Form (TEIQue-SF) created by Petrides (2009) adapted to the Slovak conditions by Kaliská, Nábělková and Salbot (2015) of career decidedness and career decision self-efficacy above the career decision-making difficulties by correlation and regression analysis. Career decision-making difficulties were assessed by the Emotional and Personality Career Decision-Making Difficulties Scale (EPCD; Saka, Gati \& Kelly, 2008), career decidedness was assessed by Lounsbury and Gibson's Career Decidedness Scale (CDS, 2011), career decision self-efficacy by the Career Decision Self-Efficacy Scale-Short Form (CDSES-SF, Betz et al., 1996). The research sample consisted of 322 high school students (average age: 17.7 /SD=.46/; 58.4\% of females). Results proved that high trait EI is significantly positively correlated to decidedness, to career decision self-efficacy, and significantly negatively to all the factors and global level of career decision-making difficulties. Trait EI significantly predicts career difficulties over and above career decidedness and career decision self-efficacy. The results empirically support the relevance of both trait EI and career decision self-efficacy in the career decision process, with practical implications for diagnostics and intervention within career counseling, as a means to strengthen the effectiveness of the process of career decision making in career choice and in career development.
\end{abstract}

Keywords: Trait emotional intelligence, career indecision, career decidedness, career decision-making difficulties, career decision self-efficacy.

\section{Introduction}

Career decision-making is typically a stressful experience, often manifested by decision-making difficulties. It is especially important at the end of adolescence period when high school students face challenges to make a choice regarding their future studies or a work profession. Career decision-making combined with personality variables is a well-researched empirical area. However, there is a place for further exploration by incorporating the emotional intelligence (EI) construct in relation to career decision-making constructs. The relationships between EI and career decision-making is important to be explored, as the resulting information can contribute to both research-based knowledge for vocational psychology and to career guidance practice.

Career indecision is defined as difficulties encountered by individuals while making career-related decisions and refers to all problems and challenges that need to be addressed prior to, during, or after the decision-making process (Saka, Gati, \& Kelly, 2008, 403). It can be differentiated between temporary, developmental indecision on one side and more pervasive, chronic indecisiveness derived predominantly from personality and emotional factors. Saka, Gati and Kelly (2008) developed a theoretical framework for analysing the emotional and personality-related aspects of career decision-making difficulties. They proposed a hierarchical taxonomy with three major clusters of difficulties - pessimistic views, anxiety, and self-concept and identity - that are then subdivided into 11

${ }^{1}$ The research was supported by Scientific Grant Agency in Slovakia, grant project VEGA No. 1/0654/17. 
specific categories based on finer distinctions. The first major cluster - pessimistic views - refers to negative cognitive biases and perceptions. The second major cluster is defined as anxiety refering to the possible effects of anxiety on specific aspects of decision-making process. The third major cluster is labelled as self-concept and identity, which refers to developmental personality aspects of the individual. Based on the proposed model, the authors developed the Emotional and Personality Career Difficulties Scale $(E P C D)$ and empirically verified the above-mentioned model. It has been verified within the Slovak context as well (Sollárová, 2016; Sollárová \& Kaliská, 2018).

The literature reveals a growing interest in studying individual variables associated with the career decision-making process. In the search for variables that potentially affect the career decision-making process, the importance of self-perceptions, or how the individual views himself or herself, has emerged as a recent focus of research. Bandura's concept of self-efficacy was integrated into the career decision-making process by Hacket and Betz (1981) and defined "career decision self-efficacy" as an individual's belief that s/he is capable of successfully completing tasks and specific behaviors required in career decision-making (Taylor \& Betz, 1983). A meta-analysis by Choi et al. (2012) investigated the relationship between career decision-making self-efficacy and a selection of related variables including gender, age, race, self-esteem, vocational identity, career barriers, peer support, vocational outcome expectations, and career indecision. Career indecision was found to have a strong negative correlation with career decision self-efficacy.

Apart from personality traits, the specific role of career decision-making process is generally recognized and agreed upon among researchers (Martincin \& Stead, 2015), emotional intelligence (EI) represents an additional potentially critical variable in the career decision-making process (Di Fabio \& Palazzeschi, 2009), yet being rarely studied. In studying the role of EI in career decision-making difficulties, Mayer-Salovey's ability-based model and Bar On's model as the so-called mixed model linking EI with personality and abilities, have been mostly investigated (Di Fabio, \& Palazzeschi, 2009; Di Fabio, Palazzeschi, \& Bar-On, 2012). The studies indicate that EI is inversely associated with decision-making difficulties and that EI also explains a significant percentage of the incremental variance when compared with personality traits in explaining the impact on the career decision-making difficulties involved in Gati's model (Di Fabio, \& Palazzeschi, 2009). Research exploring the relations between EI and career difficulties is still limited, especially the relations between trait EI models (e.g., Schutte or Petrides' model). Thus, investigating a role of trait EI as another EI model offers a new research opportunity. Trait EI, investigated in this study, is explained by its author, Petrides (2009), as a constellation of emotion-related self-perceptions and dispositions located at the lower levels of personality hierarchies. The model consists of 15 facets (13 of them forming 4 factors: emotionality, sociability, well-being and self-control and 2 independent facets stand by themselves) forming the global level of trait EI (more detailed characteristics of the factors in Petrides, 2009; Kaliská \& Nábělková, 2015). Petrides also created questionnaires to measure trait EI (Trait Emotional Intelligence Questionnaire - TEIQue) for three developmental stages (children, adolescents, and adults) of two forms (short and long form), adapted in Slovakia by Kaliská, Nábělková, \& Salbot (2015).

There have been conducted very few investigations on EI in relation to career indecision, specifically analyzing the relationship between trait EI based on Petrides' model and emotional and personality-related aspects of decision-making difficulties based on Saka, Gati, and Kelly's model (2008). The first attempt of the authors (Sollárová, \& Kaliská, 2018) showed significant positive, though weak, relationships between global trait EI level and career decidedness, however significant negative moderate to strong relationship between global trait EI level and global career decision-making difficulties as well as its three factors (especially factor of self-concept and identity) in the sample of 156 Slovak high school students. Trait EI predicted a significant almost $7 \%$ of unique variance in career decision-making difficulties after controlling for decidedness level with remaining significant negative moderate correlation.

\section{Objectives}

The present study aims to analyse the relationship between emotional intelligence, career decidedness, career decision self-efficacy and career decision-making difficulties. More succinctly, the purpose of the study is to verify whether EI can explain a significant percentage of incremental variance compared with career decidedness and career decision self-efficacy in explaining career decision-making difficulties. We questioned the following:

First, what is the relationship between trait emotional intelligence, career decidedness, career decision self-efficacy and career decision-making difficulties? Based on our reading of the literature we hypothesized that

(H1) individuals with higher trait emotional intelligence scores would display higher levels of career decidedness.

(H2) individuals with higher trait emotional intelligence scores would display higher levels of career decision-making self-efficacy. 
(H3) individuals with higher trait emotional intelligence scores would display lower levels of career decision-making difficulties.

Second, what clusters of career decision-making difficulties as defined by Saka, Gati, and Kelly's model (2008) of emotional and personality-related decision-making difficulties are most associated with total trait emotional intelligence as defined by Petrides?

Third, can trait emotional intelligence predict a significant percentage of incremental variance above career decidedness and career decision self-efficacy in explaining career decision-making difficulties? We hypothesized that (H4) trait emotional intelligence will explain a significant percentage of incremental variance compared with career decidedness and career decision-making self-efficacy in predicting the career decision-making difficulties.

\section{Methods}

Research sample. The research sample consisted of 322 high school students (average age: $17.7 / \mathrm{SD}=.46 / ; 58.4 \%$ of females) from three high schools of the central Slovak region. The research sample was obtained by targeted and occasional sampling as a part of professional orientation testing. Either the parental or individual (18-year-old ones do not need parental approval) informed consent was signed voluntarily two weeks before testing.

Research methods. Trait EI was assessed by the short Slovak version of the Trait Emotional Intelligence Questionnaire-Short Form (TEIQue-SF, Kaliská, Nábělková, \& Salbot, 2015) created by Petrides (2009). The instrument consists of 30 items answered by a seven-point Likert scale (1 - completely disagree to 7 - completely agree), a higher rating indicate a higher level of TEI; Cronbach a was .83.

To evaluate career decision-making difficulties, participants responded to the Slovak version of the Emotional and Personality Career Difficulties Scale (EPCD, Saka, Gati, \& Kelly, 2008). The scale consists of 53 items, each item representing one of the 11 difficulty categories, answered on a 9-point scale ( 1 - does not describe me to 9 - describes me well), a higher rating indicates a higher level of difficulty. The total score and the sum from the three subscales were calculated. Cronbach $\alpha$ was 0.945 .

To evaluate career in/decidedness, the Career Decidedness Scale (CDS; Lounsbury, \& Gibson, 2011) was used. It is a 5-item one-dimenzional scale with the score range from 6 to 30, a higher score indicates a higher decidedness. Cronbach $\alpha$ was .949.

Career decision self-efficacy was assessed by The Career Decision Self-Efficacy Scale - Short Form (CDSE-SF; Betz, Klein, \& Taylor, 1996). The scale includes 25 items divided by five scales, namely, accurate self-appraisal, gathering occupational information, goal selection, making plans for the future, and problem solving. The answers were obtained using a scale with five alternatives, ranging from $1=$ not al all confident to $5=$ totally confident. Higher scores indicated higher levels of career decision self-efficacy. Cronbach $\alpha$ was 907.

Data analysis. Descriptive statistics, Pearson $\mathrm{r}$ correlations, and a hierarchical regression analysis were performed.

\section{Results}

The basic descriptive indicators for global trait EI assessed by TEIQue-SF questionnaire, for three main factors and global level of career difficulties assessed by EPCD, the level of decidedness by CDS and career decision self-efficacy by CDSE-SF of our research sample are presented in Table 1.

Table 1. Descriptive indicators of all variables in a sample of the Slovak adolescents $(N=322)$.

\begin{tabular}{|c|c|c|c|c|c|c|c|c|}
\hline & & Min & Max & $\mathrm{AM}$ & $\mathrm{SD}$ & Skewness & Kurtosis & $\alpha$ \\
\hline TEIQue-SF & Global Trait EI & 2.47 & 6.63 & 4.83 & .72 & -.473 & .345 & .853 \\
\hline \multirow{4}{*}{ EPCD } & Pessimistic views & 1.50 & 7.33 & 4.89 & 1.01 & -.253 & .117 & \multirow{4}{*}{.944} \\
\hline & Anxiety & 1.19 & 9.00 & 5.32 & 1.87 & -.338 & -.673 & \\
\hline & Self-concept and Identity & 1.00 & 7.94 & 4.19 & 1.34 & .119 & -.357 & \\
\hline & $\begin{array}{l}\text { Global Career } \\
\text { Difficulties }\end{array}$ & 1.79 & 7.89 & 4.89 & 1.22 & -.280 & -.379 & \\
\hline CDS & Decidedness & 1.00 & 5.00 & 2.68 & 1.12 & .420 & -.878 & .940 \\
\hline CDSE & $\begin{array}{l}\text { Career Decision Making } \\
\text { Self-efficacy }\end{array}$ & 1.84 & 4.88 & 3.47 & .59 & -.075 & -.308 & .907 \\
\hline
\end{tabular}

We can also conclude all of the observed inner consistencies of the instruments used estimated by Cronbach's alpha coefficients reach acceptable values. Statistical analysis of skewness and kurtosis of the variables proves the normal distribution of the analyzed variables therefore the relation estimate was 
carried out using parametric correlation analysis. Pearson's correlation coefficient (r) enables to determine the direction and strength of relations between variables presented in Table 2.

Table 2. Correlation analysis of the variables $(N=322)$.

\begin{tabular}{|c|c|c|c|c|c|c|c|}
\hline & & 2 & 3 & 4 & 5 & 6 & 7 \\
\hline TEIQue-SF & 1 Global Trait EI & $-.307^{* * * *}$ & $-.343^{* * * *}$ & $-.608^{* * *}$ & $-.476^{* * *}$ & $.247^{* * *}$ & $.552^{* * * * *}$ \\
\hline \multirow{4}{*}{ EPCD } & 2 Pesimistic views & 1.00 & $.547^{* * *}$ & $.472^{* * * *}$ & $.682^{* * *}$ & $-.426^{* * *}$ & $-.343^{* * *}$ \\
\hline & 3 Anxiety & & 1.00 & $.683^{* * *}$ & $.946^{* * *}$ & $-.766^{* * *}$ & $-.536^{* * *}$ \\
\hline & $\begin{array}{l}4 \text { Self-concept and } \\
\text { Identity }\end{array}$ & & & 1.00 & $.853^{* * *}$ & $-.559^{* * * *}$ & $-.598^{* * *}$ \\
\hline & $\begin{array}{l}5 \text { Global Career } \\
\text { Difficulties }\end{array}$ & & & & 1.00 & $-.738^{* * *}$ & $-.595^{* * *}$ \\
\hline CDS & 6 Decidedness & & & & & 1.00 & $.526^{* * *}$ \\
\hline CDSE & $\begin{array}{l}7 \text { Career Decision Making } \\
\text { Self-efficacy }\end{array}$ & & & & & & 1.00 \\
\hline
\end{tabular}

Referring to the correlation analysis it can be stated that global level of trait EI was negatively correlated to all the scales and global level of career difficulties (supporting H3). The strongest negative and significant correlation was between global level of trait EI and EPCD cluster of Self-Concept and Identity within career decision-making difficulties (Q2). The global trait EI is in (positive) weak significant relation to the level of decidedness as hypothesized in $\mathrm{H} 1$, and in positive significant strong relation to career decision-making self-efficacy supporting the hypothesis $\mathrm{H} 2$.

Further on there was a hierarchical two-step regression analysis conducted to determine if global level of the career difficulties as dependent variable could be predicted by the decidedness, career decision-making self-efficacy level and global trait EI level to support also the incremental validity of trait EI. The results are presented in Table 3.

Table 3. Hierarchical regression analysis.

\begin{tabular}{|c|c|c|c|}
\hline & \multicolumn{3}{|c|}{ Career Difficulties } \\
\hline & $\begin{array}{l}\text { Step 1 } \\
\text { Step } 2 \\
\text { Step } 3\end{array}$ & $\begin{array}{r}\mathrm{F} \\
\mathrm{F}_{\text {change }}(2,3 \\
\mathrm{F}_{\text {change }}(3,3\end{array}$ & $\begin{array}{l}29^{* * * *}, \mathrm{R}^{2} \text { adj. }=.545 \\
\mathrm{R}^{2} \text { adj. }=.606, \mathrm{R}^{2} \text { change }=.062 \\
\mathbf{R}^{\mathbf{2}} \text { adj. }=\mathbf{. 6 4 9}, \mathbf{R}_{\text {change }}=\mathbf{. 0 4 4}\end{array}$ \\
\hline & Beta & $\mathrm{t}$ & Partial correlations \\
\hline $\begin{array}{l}\text { Decidedness } \\
\text { (Step 1) }\end{array}$ & -.739 & $-19.176^{* * *}$ & -.739 \\
\hline $\begin{array}{l}\text { Decidedness } \\
\text { Career Decision Making }\end{array}$ & -.586 & $-13.887^{* * \% *}$ & -.623 \\
\hline $\begin{array}{l}\text { Self-efficacy } \\
\text { (Step 2) }\end{array}$ & -.292 & $-6.915^{* * *}$ & -.369 \\
\hline Decidedness & -.604 & $-15.126^{* * * *}$ & -.656 \\
\hline $\begin{array}{l}\text { Career Decision Making } \\
\text { Self-efficacy }\end{array}$ & -.142 & $-3.051^{* *}$ & -.173 \\
\hline $\begin{array}{l}\text { Trait EI } \\
\text { (Step 3) }\end{array}$ & -.253 & $-6.211^{\text {**** }}$ & -.336 \\
\hline
\end{tabular}

A three-step hierarchical regression was performed to investigate the prediction potential of trait EI of career decision-making difficulties level and at the same time to prove the incremental influence of trait EI over and above the decidedness and career decision-making self-efficacy level. The decidedness was entered at step 1, decidedness and career decision-making self-efficacy at step 2 and trait EI was added on its own at step 3. At step 1, the model was statistically significant and decidedness level predicted almost $55 \%$ of the variance in career difficulties level. Then at step 2, the career decision-making self-efficacy was added, and the model remained statistically significant predicting $61 \%$ of the variance in career difficulties level. And as the last step, the trait EI was entered on its own. The model was again found to be significant, and trait EI remained a significant negative predictor of career decision-making difficulties, over and above decidedness and career decision-making self-efficacy level (H3). Trait EI predicted a significant almost $4 \%$ of unique variance in career decision-making difficulties after controlling for decidedness and career decision-making self-efficacy level supporting incremental validity of trait EI with remaining partial medium strength correlation of $r=-.336$. 


\section{Discussion}

Relationships between global trait emotional intelligence (TEI) as measured by the Petrides' TEIQue-SF (2009), career decidedness as measured by Lounsbury and Gibson's CDS (2011), career decision self-efficacy by Betz et al.'s CDSES-SF and career decision-making difficulties as measured by Saka, Gati and Kelly's EPDS scale were investigated in a population of the Slovak high school students.

As expected ( $\mathrm{H} 1$ and $\mathrm{H} 2$ ), individuals who showed higher global trait emotional intelligence displayed higher career decidedness and higher career decision-making self-efficacy level. The result supports our previous findings (Sollárová, 2016; Sollárová \& Kaliská, 2018) where the level of emotional and personality-related aspects of career decision-making difficulties was differentiated by the level of undecidedness of high school and university students where students with higher level of undecidedness (related to their study and profession choice) showed higher level of career decision-making difficulties.

As expected (H3), individuals who showed higher global trait emotional intelligence level displayed less career decision-making difficultes, both in overall difficulties and in all three areas of difficulties as defined in the model by Saka, Gati, and Kelly (2008). The strongest negative and significant correlation was found between global level of trait EI and the third major area of difficulties defined as "self-concept and identity" (Q2).

Prediction of the emotional and personality-related career decision-making difficulties by the decidedness and career decision-making self-efficacy level and over and above by the global trait EI level (H4) was investigated and examined by means of hierarchical regression analysis. Our research supported that global trait EI significantly predicted higher level of career decidedness and career decision self-efficacy and lower level of emotional and personality-related career-decision-making difficulties, over and above the decidedness and career decision self-efficacy level. The findings support the role of trait EI as a predictor of also more stable, pervasive emotional and personality-related aspects of career decision-making difficulties (as defined in the model by Saka, Gati, \& Kelly, 2008), above and over studied career-related construct of self-efficacy. The results also empirically support the relevance of both trait EI and self-efficacy (generalized and career decision) in the career decision process, with practical implications for diagnostics and intervention within career counseling, as a means to strengthen the effectiveness of the process of career decision making in career choice and in career development.

\section{References}

Betz, N. E., Klein, K. L., \& Taylor, K. M. (1996). Evaluation of a short-form of the Career Decision-Making Self-Efficay Scale. Journal of Career Assessment, 4, 413-428.

Choi, B. Y., Park, H., Yang, E., Lee, S. K., Lee, Y., \& Lee, S. M. (2012). Understanding career decision self-efficacy. A meta-analytic approach. Journal of Career Development, 39, 443-460.

Di Fabio, A., \& Palazzeschi, L. (2009). Emotional intelligence, personality traits and career decision difficulties. International Journal for Educational and Vocational Guidance (9), 135-146.

Di Fabio, A., Palazzeschi, L., \& Bar-On, R. (2012). The role of personality traits, core self-evaluation, and emotional intelligence in career decision-making difficulties. Journal of employment counseling (49), 118- 129.

Hacket, G., \& Betz, N. E. (1981). A self-efficay approach to the career development of women. Journal of Vocational Behavior, 18, 326-339.

Kaliská, L., \& Nábělková, E. (2015). Psychometrické vlastnosti a slovenské normy Dotazníkov črtovej emocionálnej inteligencie pre deti, adolescentov a dospelých. Banská Bystrica: Belianum.

Kaliská, L., Nábělková, E., \& Salbot, V. (2015). Dotazníky črtovej emocionálnej inteligencie TEIQue-SF/TEIQue-CSF: manuál k skráteným formám. Banská Bystrica: Belianum.

Lounsbury, J. W., \& Gibson, L. W. (2011). Career Decidedness Scale. Knoxville, TN USA, Resource Associates, Inc.

Martincin, K. M., \& Stead, G. B. (2015). Five-Factor Model and Difficulties in Career Decision Making: A Meta-Analysis. Journal of Career Assessment, 23(1), 3-18.

Petrides, K.V. (2009). Trait Emotional Intelligence Questionnaire (TEIQue). Technical Manual. London: London Psychometric Laboratory.

Saka, N., Gati, I., \& Kelly, K. R. (2008). Emotional and Personality-Related Aspects of Career-Decision-Making Difficulties. Journal of Career Assessment 16(4), 403-424.

Sollárová, E. (2016). Ťažkosti v kariérovom rozhodovaní pred a po druhej smerovej vol'be. Rozhodovanie $v$ kontexte kognície, osobnosti a emócií V., Nitra, UKF, 20-37.

Sollárová, E. \& Kaliská, L. (2018). Trait emotional intelligence as a predictor of career indecision. Psychological applications and trends 2018: InPACT 2018. Lisbon: InScience Press, 102-106.

Taylor, K.M., \& Betz, N.E. (1983). Applications of self-efficacy theory to the understanding and treatment of career indecisiion. Journal of Vocational Behavior, 22, 63-81. 